\title{
Urgences
}

\section{" F " pour... " F "}

\section{Suzanne Lavoie}

\section{Numéro 10, 2e trimestre 1984}

\section{Spécial fantasmes}

URI : https://id.erudit.org/iderudit/025154ar

DOI : https://doi.org/10.7202/025154ar

Aller au sommaire du numéro

\section{Éditeur(s)}

Urgences

\section{ISSN}

0226-9554 (imprimé)

1927-3924 (numérique)

Découvrir la revue

\section{Citer ce document}

Lavoie, S. (1984). " F " pour... " F ". Urgences, (10), 33-37.

https://doi.org/10.7202/025154ar d'utilisation que vous pouvez consulter en ligne.

https://apropos.erudit.org/fr/usagers/politique-dutilisation/ 


\section{SUZANNE LAVOIE}

${ }^{66} \mathrm{H}^{99}$ DOU11.. ${ }^{66} \mathrm{H}^{99}$ 
"F" pour... "F"

II lui fallait, pour écrire son roman fantastique, un certain décor, un certain ordre dans son environnement qui se muait docilement, pour la circonstance, en un univers de signes de plus en plus précis.

Combien de fois n'avait-elle déclaré, le geste on ne peut plus ostentatoire et le ton caverneux: je ne suis pas une femme de théâtre, JE suis théâtrale. Dans une même envolée, elle enchaînait avec sa théorie de la verticalité.

Ce soir-là, poussée par quelque agitation frénétique, elle avait revêtu son ensemble de daim noir, l'étincelle même de sa baguette de sorcière.

Elle se sentait habitée.

— Lecteur fragile, t'abstenir!

Elle ratura. Trop tôt.

Le feu des bouées se détachait maintenant des lumières lointaines de la côte. L'animal repu occupait la zone aveugle de la passerelle. La nuit était là. II allait monter la garde. Ce soir, pas question de se laisser aller à l'introspection. À I'affût du moindre bruit, elle crut entendre la sonnerie du téléphone. "Sylvie-Anne", pensa-t-elle, pour se ressaisir aussitôt.

L'île... son île! Depuis longtemps terreau de son inspiration. Jamais l'isolement de ce lieu ne lui avait paru si hypnotique. Encore temps de changer de cap. Mais c'était plus fort qu'elle. Pourtant... II lui était impossible d'asseoir une ligne stable.

Quelque chose vacillait. L'ombre d'une fuite. Désir. Mesurant chacun de ses gestes, elle se rendit à l'étagère et déposa sa montre dans l'une des boîtes de sa collection, les comptant de gauche à droite. Choisit la rose dont elle ajusta minutieusement le couvercle qu'elle caressa de droite à gauche. Rite 
voluptueux. "Complétude logique de l'être et de la forme".

- Pour la matière du symbole...

Rapetisser, rapetisser, rapetisser, encore et encore. Le sujet risquait de se perdre. Le doute. Plus que le doute, la peur. En escalade. L'oreille tendue. Étranglée. Grande, il lui fallait aborder la grandeur par la grandeur. Vaincre cette certitude qu'elle ne dominait plus la totalité de SON royaume, du haut de SON phare désaffecté. La lumière ne jaillissait plus.

Le choc de la vague sur le récif l'agressait. Des bribes. Sublimation. Une écriture hachurée, inégale, ne lui appartenant pas. Elle était de plus en plus certaine qu'on violait son territoire. L'étranger rôdait. Son île était aliénée.

- Je viens trop peu souvent ici. L'ensemble se disloque. Je le sens très bien.

En alternance, des mâchoires, des chevelures et des membres tordus s'introduisaient sans pudeur dans la pièce, leurs ombres comme leurs reflets se moulant au mur de verre unique de la tour marine.

Vivre à l'intérieur d'une lanterne impliquait ce genre de cohabitation. Toutefois, elle ne reconnaissait plus ce monde étrange déjà si familier, si conforme, dans lequel son imaginaire avait grandi. Les dimensions n'étaient plus proportionnelles.

La vague cognait maintenant, elle perdait pied.

- Un vendredi treize. J'ai dépassé ma limite.

Treize à table. Treize femmes. Toutes plus ou moins voyantes. Voyantes qui ne se gênaient pas, d'ailleurs, pour dire l'aventure, bonne ou mauvaise. Elle ne pouvait blâmer personne, cette idée était la sienne.

Parti tourner un film sur la chasse aux phoques, un 
homme veillait de loin à sa vie.

— La belle aventure!

Vendredi treize. Elle frissonna. Elle tenta de déposer son stylo, mais sa main refusa de lâcher prise. Le rouage du maléfice était engagé. Il devait bien y avoir une victime; le bourreau allait agir sans aide. La mauvaise aventure.

“Désespacée"...

S'attendant au pire et incapable de quelque mouvement, elle avait senti le givre lui envahir la nuque. Ses forces la quittaient. Elle se trouvait à mi-chemin entre l'engelure et la pensée féconde. Mais celle-ci cédait devant la rigidité croissante de ses muscles.

Elle allait s'abandonner à elle-même quand un long sifflement scinda les lieux déjà de glace.

La bête se réveilla d'un bond, donnant de toute sa hauteur d'homme contre la paroi transparente de son refuge.

- Allez-vous-en! Allez-vous-en! cria la femme au même moment, d'une voix qui heurta sec la barrière hermétique de ses dents. Trop tard!

Dehors le brouillard recouvrait terre et eau. Le grésil venait droit de l'est.

Elle tenait les yeux à peine ouverts tandis qu'elle avançait péniblement. Elle avait passé un temps d'éternité à la reconnaissance. Impossible de découvrir ce que cachait cette envoûtante substance. Au loin, aucune trace des bouées.

Soudain, la plainte se fit plus précise. La femme continua sa marche en direction de l'appel, accélérant le pas, mue par la certitude que la rupture du silence avait été nécessaire.

Son entreprise prenait une allure militaire. La distance lui 
rendait son être, une respiration à la fois. Elle irait jusqu'au bout.

Tout ce temps, rivé entre l'index et le majeur de sa main droite, l'instrument de son oeuvre accompagnait la cadence de ses mouvements. L'air se raréfiait. Exténué, son corps tout entier se laissait griser par une sensation de mouvance bienfaisante, absolue, que semblait confirmer la vision d'une indéfinissable muraille. Dans son espace.

Peut-être fallait-il mettre un point final...

L'individu s'adressa à la femme sans enflure. L'inconnue serait-elle partie à la recherche de quelqu'un... D'un chasseur, peut-être... L'énigme demeurait statique. La banquise s'approchait depuis plusieurs jours. Oui, oui, sans doute. Une illusion d'optique. L'ignorance des lieux... A la vitesse des vents du large, la pluie l'a rapidement enveloppée d'une cage de verre. À en croire la frayeur sur ses traits.

- Debout, par-dessus le marché. II faudra attendre le printemps. On se sent trop impuissant devant cet événement. Excusez-nous, Madame.

Le sommeil la gagnant, elle se dirigea du côté de la passerelle et fit entrer sa bête. Le jour irriguait sa lanterne.

Elle salua le retour de la lumière. 